\title{
The relationship of amelogenesis imperfecta and nephrocalcinosis syndrome
}

\author{
Zuhal Kırzıoglu, K. Gorkem Ulu, M. Tugrul Sezer, Seref Yüksel
}

Research Assistant in Süleyman Demirel University, Faculty of Dentistry, Department of Paediatric Dentistry, Isparta/Türkiye

Correspondence:

Faculty of Dentistry,

Department of Paediatric Dentistry,

Isparta/Türkiye,

gorkemulu@yahoo.com

Received: $11 / 11 / 2008$

Accepted: 20/05/2009

\author{
Kırzıoglu Z, Ulu KG, Sezer MT, Yüksel S. The relationship of amelogen- \\ esis imperfecta and nephrocalcinosis syndrome. Med Oral Patol Oral Cir \\ Bucal. 2009 Nov 1;14 (11):e579-82. \\ http://www.medicinaoral.com/medoralfree01/v14i11/medoralv14i11p579.pdf \\ Article Number: $2555 \quad$ http://www.medicinaoral.com/ \\ (C) Medicina Oral S. L. C.I.F. B 96689336 - pISSN 1698-4447 - eISSN: 1698-6946 \\ eMail: medicina@medicinaoral.com \\ Indexed in: \\ -SCI EXPANDED \\ -JOURNAL CITATION REPORTS \\ -Index Medicus / MEDLINE / PubMed \\ -EMBASE, Excerpta Medica \\ -SCOPUS \\ -Indice Médico Españo
}

\begin{abstract}
Aim: To analyze the prevalence and associated oral findings of nephrocalcinosis in a group of patients affected with amelogenesis imperfecta (AI). The relationship between types of AI and nephrocalcinosis were also evaluated. Design: This study examines patients who were referred to Pediatric Dentistry Department of SDU between the years of 2002-2007 and who, upon clinical and radiological examination, were diagnosed with AI and treated. Patients were offered information about the possibility of nephrocalcinosis syndrome. Patients who agreed to have tests carried out on their renal system were advised to visit the department of nephrology at the clinic. Results: Suspicious radiopacity was observed during renal ultrasonography of a controlled number of patients with hypoplastic type AI. Laboratory results revealed low Ca values (100-300 mg/days) and normal P values (0.4-1.3 $\mathrm{g}$ /days). Delayed eruption, gingival hyperplasia, pulp stones and orthodontic problems were also observed in the same patient groups. Conclusion: Although renal findings were observed in a few patients, pediatric dentists are the doctors who are the first to have early contact with this patient group. Because of the potential risk of nephrocalcinosis, early diagnosis may offer good prognosis.
\end{abstract}

Key words: Amelogenesis imperfecta, nephrocalcinosis.

\section{Introduction}

Amelogenesis imperfecta (AI) describes a group of inherited disorders that affects the quality and quantity of primary and/or permanent enamel and which may be associated with morphologic or biochemical changes elsewhere in the body. Amelogenesis imperfecta may affect all or only some of the teeth in the primary and/ or permanent dentition (1). AI shows autosomal dominant, autosomal recessive, sexlinked and sporadic inheritance patterns, as well as sporadic cases (2).

Although AI is generally considered to primarily affect dental enamel, other oral and dental stigmata which is including unerupted teeth, anterior open bite, pulpal calcifications, interradicular dentinal dysplasia, root and crown resorption, cementum deposition, truncated roots, gingival overgrowth and taurodontism have been shown to coexist (1-3). In addition, AI is a feature of several multiorgan syndromes, but is pathognomonic of only a few (1).

Nephrocalcinosis, which means an increase in the calcium content of the kidneys, is an extremely rare syndrome and its association with AI has been reported in just a few families. However the prognosis associated with this syndrome has not been established (1). 
The importance of syndrome diagnosis and recognition in this condition is in guiding pediatric dentistry, who meets this patient group in early ages, to recognize the possibility of the other anomalies in patients AI. The purpose of this study is to assess the prevalence and its associated oral findings of nephrocalcinosis in a group of AI patients.

\section{Material and Methods}

We conducted an electronic literature search on the keywords 'amelogenesis imperfecta' and 'nephrocalcinosis' and these revealed an extremely rare association of AI with nephrocalcinosis, before in the course of preparation of this paper.

Twenty-eight patients, who were referred to Pediatric Dentistry Department of Süleyman Demirel University Faculty of Dentistry between the years of $2002-2007$, were diagnosed as AI after assessment of anamnesis, clinical and radiological examination by experienced. Genetic examination can not be done because of high costs. As a precautionary measure, information about nephrocalcinosis syndrome possibility was given to the patients who had treated and continued the treatments and controls. They were advised to attend to the department of nephrology clinic. Because of some problems only 17 of the patients accepted to control their renal system. Urinary system graphy, renal ultrasonography and laboratory examination which was analyzed by the same author were taken from associated clinics at the Faculty of Medicine Department of Nephrology. Patient's files were evaluated once more for delayed eruption, gingival hyperplasia, pulpal obliteration and orthodontic problems such as anterior openbite.

\section{Results}

After clinical and radiological examination 28 patients were classified by the most accepted classification system identifying three main AI types: hypoplastic, hypocalcified and hypomaturation (4). Twenty of them were hypoplastic, 7 of them were hypocalcified and others were hypomaturation. Delayed eruption (4 patients) gingival hyperplasia (5 patients), pulp stones (3 patients) and orthodontic problems (11 patients) were observed at oral examination of 17 patients who were referred to the neprohology clinic and all of these patients had hypoplastic type AI (Fig. 1).

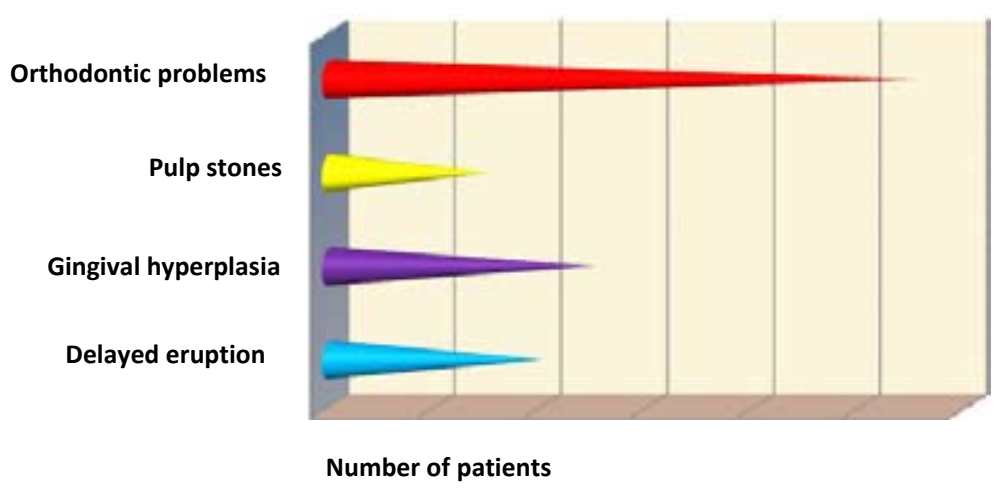

Fig. 1. Oral findings of AI patients (n:17).

Table 1. Nefrologic and oral findings of 5 AI patients.

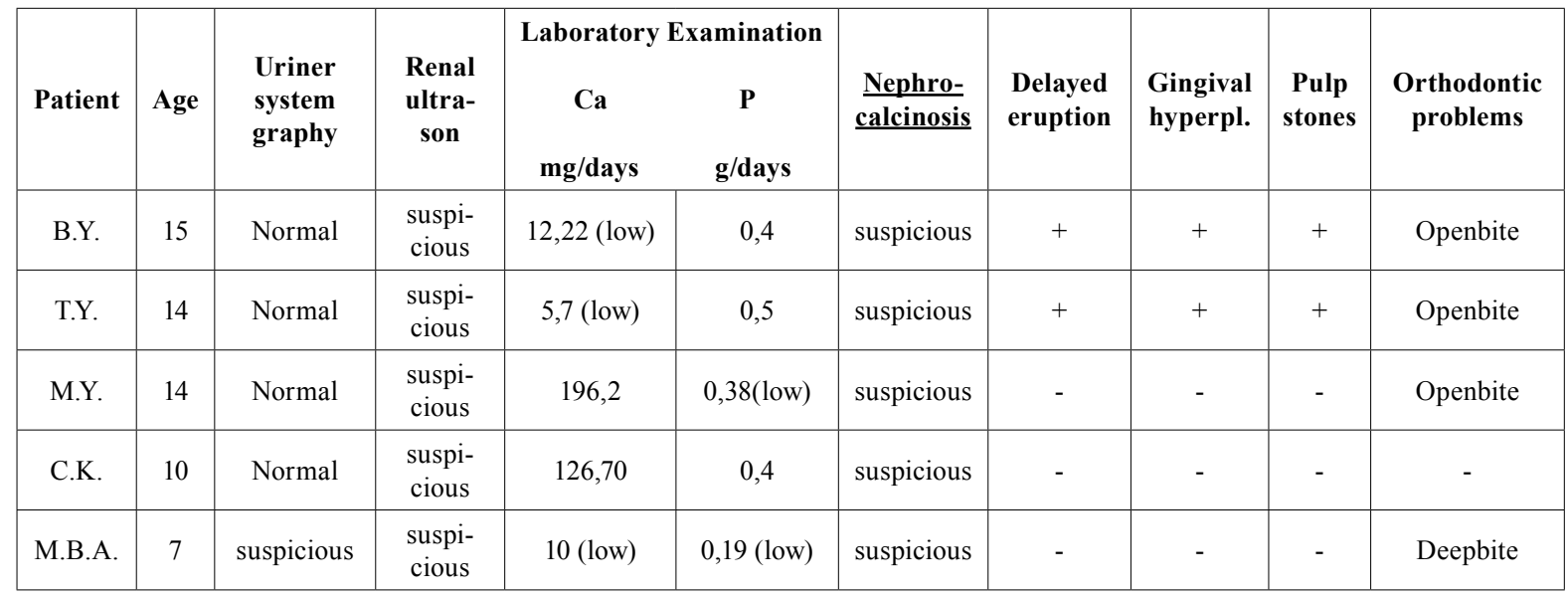



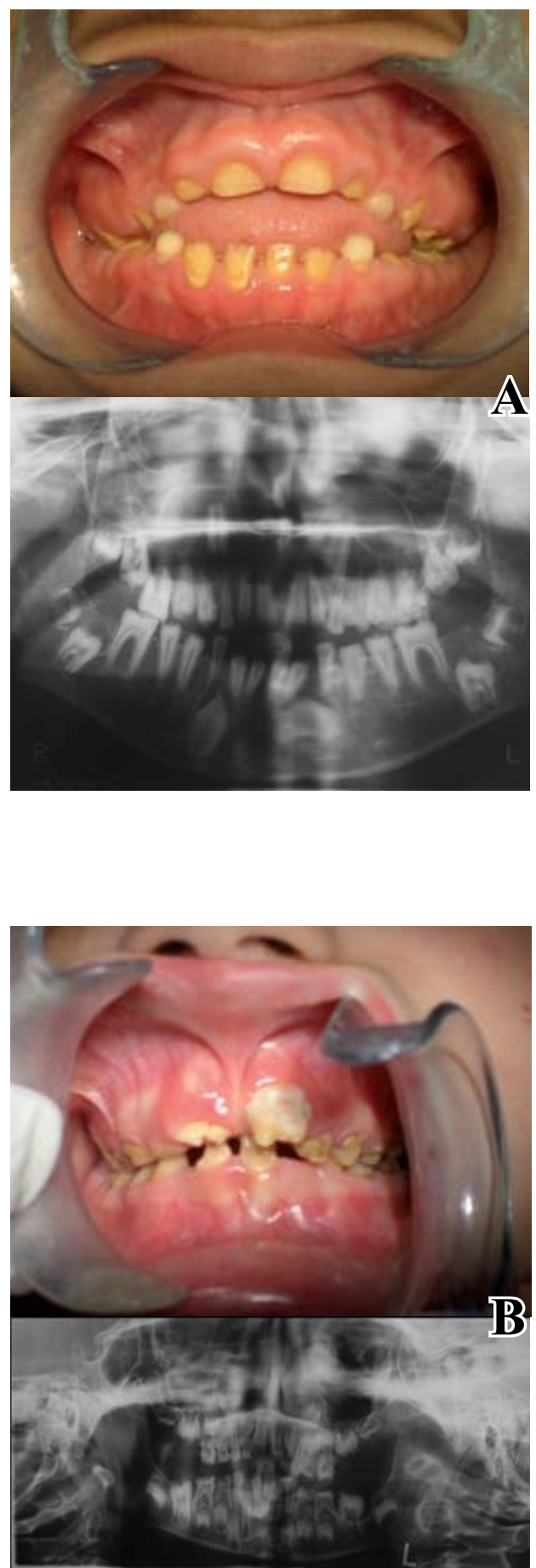

Fig. 2, a, b: Dental panoramics and clinic photos taken by 2 patients.
Uriner system graphy of one patient and renal ultrasonography of 5 patients demonstrated suspicious radiopacity. Laboratory results of 3 patients showed low Ca values (100-300 mg/days) and 2 patients showed low $\mathrm{P}$ values (0,4-1,3 g/ days) (Table 1, Fig. $2 \mathrm{~A}$ and $\mathrm{B})$. In this group, 2 of them were occuring in a sibling pair. Although siblings showed common oral findings, other 3 patients had different symptoms. These groups were followed up by nephrology departments.

\section{Discussion}

The syndrome of AI and nephrocalcinosis has been previously reported in only 14 cases (including eight siblings), (1, 5-12). Although AI and nephrocalcinosis may therefore be an extremely rare syndrome, untreated nephrocalcinosis is known to be associated with significant morbidity. Patients' family who had this syndrome was not detected until they were well into adulthood.

The earlier paper appeared by Mac-Gibbon (5) in which $\mathrm{AI}$ and nephrocalcinosis were reported in a young woman when her 26-year-old brother with nephrocalcinosis and similar teeth died. In the cases reported, renal function was stable until the patient was 16 years of age, but progressive renal failure and death ensued.

The second paper described by Lubinsky et al. (6) in 1985, in two siblings had AI and nephrocalcinosis, impaired renal concentration and possible abnormality of calcium metabolism.

Hall et al. (7) described another sibling pair with autosomal recessive hypoplastic AI and nephrocalcinosis. Both had normal 24-h urinary excretion of calcium and phosphate.

More recently Hunter L et all (1) reported case in which hypoplastic AI with delayed of eruption of the permanent teeth was shown to be associated with renal calcification.

In the present cases suspicious renal findings almost was observed in $29 \%$ patients (n:17). Possibilities of nephrocalcinosis were detected after the diagnosis of AI. The common oral characteristics are the presence of thin or absent enamel, delayed tooth eruption, presence of pulpal calcifications may be signs for the diagnosis of nephrocalcinosis (7-9). Its importance is known to be associated with significant morbidity with unrecognized and untreated nephrocalcinosis.

Due to the importance of a renal involvement, kidney ultrasound should be performed in all AI patients in order to exclude nephrocalcinosis and to determine if this alteration is exclusive of this rare syndrome or can be found in other AI forms (10).

In some of the previous case reports, it has been suggested that children with apparently autosomal recessive AI should, at least, have a renal ultrasound examination to exclude such pathology $(8,9)$.

The combination of AI and nephrocalcinosis may sug- 
gest two hypotheses. First hypothesis suggests that there is an abnormality in the interstitial matrix, which leads to dystrophic calcification in the kidney and abnormal enamel production in the teeth (7). Another hypothesis suggests that many of the dental proteins that were believed to be tissue specific may be expressed in more than one dental tissue and also in non-dental tissues and the role of these proteins in calcium and phosphate metabolism. Further research concerning these proteins is necessary to determine if they play a role in the calcium and phosphate metabolism and renal function (10, 1315).

Those far mutations in four genes (AMELX, ENAM, KLK4 and MMP20) have been reported to cause AI (2), but the molecular defects of all forms of AI have not yet been established. So, the dentists should based on the clinical and radiographic findings when diagnosing and planning treatment for patients with $\mathrm{AI}$ and all patients with AI should undergo such an examination for nephrocalcinosis.

In summary, further research is necessary to clarify the genetic defect behind this syndrome, which combines two uncommon conditions, such as AI and nephrocalcinosis. The early diagnosis provided by the oral symptoms leads to a better renal prognosis. As a consenquence, pediatric dentists should be aware of this pathology.

\section{References}

1. Hunter L, Addy LD, Knox J, Drage N. Is amelogenesis imperfecta an indication for renal examination?. Int J Paediatr Dent. 2007; $17: 62-5$.

2. Crawford PJ, Aldred M, Bloch-Zupan A. Amelogenesis imperfecta. Orphanet J Rare Dis. 2007;2:17.

3. Sánchez-Quevedo C, Ceballos G, Rodríguez IA, García JM, Alaminos M. Acid-etching effects in hypomineralized amelogenesis imperfecta. A microscopic and microanalytical study. Med Oral Patol Oral Cir Bucal. 2006;11:E40-3.

4. Winter GB, Brook AH. Enamel hypoplasia and anomalies of the enamel. Dent Clin North Am. 1975;19:3-24.

5. Ravassipour DB, Powell CM, Phillips CL, Hart PS, Hart TC, Boyd

$\mathrm{C}$, et al. Variation in dental and skeletal open bite malocclusion in humans with amelogenesis imperfecta. Arch Oral Biol. 2005;50:61123.

6. MacGibbon D. Generalized enamel hypoplasia and renal dysfunction. Aust Dent J. 1972;17:61-3.

7. Lubinsky M, Angle C, Marsh PW, Witkop CJ Jr. Syndrome of amelogenesis imperfecta, nephrocalcinosis, impaired renal concentration, and possible abnormality of calcium metabolism. Am J Med Genet. 1985;20:233-43.

8. Hall RK, Phakey P, Palamara J, McCredie DA. Amelogenesis imperfecta and nephrocalcinosis syndrome. Case studies of clinical features and ultrastructure of tooth enamel in two siblings. Oral Surg Oral Med Oral Pathol Oral Radiol Endod. 1995;79:583-92.

9. Normand de la Tranchade I, Bonarek H, Marteau JM, Boileau MJ, Nancy J. Amelogenesis imperfecta and nephrocalcinosis: a new case of this rare syndrome. J Clin Pediatr Dent. 2003;27:171-5.

10. Dellow EL, Harley KE, Unwin RJ, Wrong O, Winter GB, Parkins BJ. Amelogenesis imperfecta, nephrocalcinosis, and hypocalciuria syndrome in two siblings from a large family with consanguineous parents. Nephrol Dial Transplant. 1998;13:3193-6.

11. Paula LM, Melo NS, Silva Guerra EN, Mestrinho DH, Acevedo
AC. Case report of a rare syndrome associating amelogenesis imperfecta and nephrocalcinosis in a consanguineous family. Arch Oral Biol. 2005;50:237-42.

12. Fu XJ, Nozu K, Goji K, Ikeda K, Kamioka I, Fujita T, et al. Enamel-renal syndrome associated with hypokalaemic metabolic alkalosis and impaired renal concentration: a novel syndrome? Nephrol Dial Transplant. 2006;21:2959-62.

13. Elizabeth J, Lakshmi Priya E, Umadevi KM, Ranganathan K. Amelogenesis imperfecta with renal disease--a report of two cases. $\mathbf{J}$ Oral Pathol Med. 2007;36:625-8.

14. Deutsch D, Leiser Y, Shay B, Fermon E, Taylor A, Rosenfeld $\mathrm{E}$, et al. The human tuftelin gene and the expression of tuftelin in mineralizing and nonmineralizing tissues. Connect Tissue Res. 2002;43:425-34.

15. Butler WT, Brunn JC, Qin C. Dentin extracellular matrix (ECM) proteins: comparison to bone ECM and contribution to dynamics of dentinogenesis. Connect Tissue Res. 2003;44:171-8.

16. Qin C, Brunn JC, Cadena E, Ridall A, Butler WT. Dentin sialoprotein in bone and dentin sialophosphoprotein gene expressed by osteoblasts. Connect Tissue Res. 2003;44:179-83. 